\title{
Central nervous system diseases and the role of the blood-brain barrier in their treatment
}

\author{
Alazne Domínguez ${ }^{1}$, Antonia Álvarez², Enrique Hilario², Blanca Suarez-Merino ${ }^{1}$ and Felipe Goñi-de-Cerio ${ }^{1 *}$ \\ ${ }^{*}$ Correspondence: goni@gaiker.es \\ 'GAIKER Technology Centre, Bizkaia, Science and Technology Park, Building 202, Zamudio 48170, Bizkaia, Spain. \\ ${ }^{2}$ Department of Cell Biology and Histology, School of Medicine and Dentistry, University of the Basque Country, E-48940 Leioa, \\ Bizkaia, Spain.
}

\begin{abstract}
The Neurodegenerative diseases, cancer and infections of the brain are becoming more prevalent in society as population become older. Nowadays, these diseases represent a major medical challenge, so neuroprotective therapeutics have the potential to play a key role in managing this growing global burden of long-term neurological care. Despite major advances in neuroscience, treatment for these diseases is still a challenging area due to the presence of the blood-brain barrier. Conventional therapeutics remain critically below levels of optimum therapeutic efficacy, since the blood-brain barrier ensures that many potential therapeutics cannot reach the central nervous system. Hence, the current challenge is to develop drug-delivery systems which ensure that drugs cross the blood brain barrier in a safe and effective manner. Robust methods to assess Central Nervous System permeation are therefore essential for drug discovery. Drug candidates can be successfully designed to cross the blood-brain barrier, but for those that can't cross it, a delivery system that facilitates the movement of drug candidate across the barrier may possibly enable this entry. In order to assess the drug capacity to cross the brain, animal models of neurological disorders are increasingly employed. This review focuses on the properties of the blood-brain barrier that restrict drug delivery to the brain as well as on some of the most hopeful strategies developed to study and enhance drug delivery across the blood-brain barrier.
\end{abstract}

Keywords: Brain diseases, blood-brain barrier, drug delivery systems, animal diseases models

\section{Introduction}

The human central nervous system (CNS) is the most complex organ. It determines our most unique human function, namely, consciousness. Its activity underlies all aspects of our behavior from basic requirements such as breathing to supporting our thoughts and feelings [1]. Brain diseases can result directly from intrinsic dysfunction of the brain or from complex interactions between the brain and the physical environment [2]. Brain and mind disorders include a wide range of common neurological and psychiatric illnesses. They afflict a very significant portion of the population, right across the life span, and are prevalent in both developed and developing countries. Likewise, these diseases pose the largest health, economic and social capital burden worldwide of any disease group [3].

While the mental and neurological disorders are responsible for about $1 \%$ of deaths, they account for almost $11 \%$ of disease burden all over the world. The extension of life expectancy and the ageing of the general populations in both developed and developing countries are likely to increase the prevalence of many chronic and progressive physical and mental conditions including neurological disorders [4] (Table 1). Brain and mind disorders actually affect as many as 1.5 billion people worldwide, and the number is expected to increase. No less than $25 \%$ of the total burden of disease in the established market economies is at present attributable to brain and mind disorders [5]. Altogether, brain disorders now affect 300 million persons and their total cost is 640 billion per year in Europe [6]. Indeed, the proportionate share of the total global burden of disease due to neurologic disorders is projected to rise to $14.7 \%$ by 2020 [7], highlighting an urgent need for more drugs to treat CNS disorders.

\section{Ageing population, brain disorders and health impact}

The nature of these brain disorders changes across the human lifespan. The young have a higher incidence of psychiatric disorders, including depression, anxiety, schizophrenia and substance abuse. In contrast, the elderly suffer particularly from neurodegenerative conditions such as dementia or stroke [8]. More widely appreciated is that the elderly suffer neurodegenerative disorders, like Parkinson (PD) and Alzheimer's disease (AD), which are increasing because of an ageing population [9].

The neurodegenerative CNS disorders, such as PD and $A D$, are among the leading causes of disability and death in the developed world [10]. The twentieth century saw a revolution in longevity. Between 1950 and 2010 life expectancy rose worldwide from 46 to 68 years and is expected to extend a further 10 years by 2050 . This demographic triumph and the fast growth of the population in the first half of the twenty-first century

(c) 2013 Goñi-de-Cerio et al; licensee Herbert Publications Ltd. This is an Open Access article distributed under the terms of Creative Commons Attribution License (http://creativecommons.org/licenses/by/3.0). This permits unrestricted use, distribution, and reproduction in any medium, provided the original work is properly cited. 
Domínguez et al. Neuroscience Discovery 2013,

Table 1. Age and sex specific prevalence rates (\%) of dementia and Parkinson in Europe. The extension of life expectancy and the ageing of the populations are likely to increase the prevalence of neurological disorders.

\begin{tabular}{ccccc}
\hline & Dementia & \multicolumn{3}{c}{ Parkinson } \\
\hline Age group (Year) & Men & Women & Men & Women \\
\hline $65-69$ & 1,8 & 1,4 & 0,7 & 0,6 \\
$70-74$ & 3,2 & 3,8 & 1 & 1 \\
$75-79$ & 7 & 7,6 & 2,7 & 2,8 \\
$80-84$ & 14,5 & 16,4 & 4,3 & 3,1 \\
$85-89$ & 20,9 & 28,5 & 3,8 & 3,4 \\
$>90$ & 32,4 & 48,8 & 2,2 & 2,6 \\
\hline
\end{tabular}

mean that the number of people over sixty will increase from about 600 million in 2000 to almost 2 billion in 2050 [11] and the proportion of people defined as older is projected to increase globally from 10 per cent in 1998 to 15 per cent in 2025 [12].

Thus, age-related diseases such as AD and PD disease will also increase. The neurodegenerative diseases are characterized by inexorably progressive deterioration in cognitive ability and capacity for independent living [13]. Constituting around the $80 \%$ of the neurologic disorders, they have drawn a lot of attention due to their irreversibility, to their lack of effective treatment, and because they accompany social and economical burdens [14]. The neurodegeneration produces a clinical syndrome called dementia, which describes a set of symptoms including loss of memory, mood changes, and problems with communication and reasoning. $A D$ is the leading cause of dementia, causing about half of all cases. This disease is characterized by a progressive decline in brain function, which typically begins with deterioration in memory [15].

$A D$ neuropathology shows two types of lesions, senile plaques and neurofibrillary tangles composed of $\beta$-amyloid. Although plaques and neurofibrillary tangles appear to be the most prevailing features of AD pathology, they alone are not sufficient to generate the significant and profound neuronal loss during disease [16]. People with $A D$ also have a shortage of the chemical acetylcholine in their brains. This chemical is involved with the transmission of messages within the brain [17]. Age is the greatest risk factor for dementia. However, dementia is not restricted to older people [18]. Since the elderly population is growing worldwide, AD is quickly becoming one of the major universal healthcare problems. Today, there are neither precise diagnostic approaches nor curative therapeutic agents available for AD. However, drug treatments that can temporarily alleviate some symptoms or slow down their progression in some people are available [19]. PD is the second most common neurodegenerative disease, affecting $1 \%$ of the population over 55 years of age. This disease is characterized by the loss of $\sim 50-70 \%$ of the dopaminergic neurons in the substantia nigra pars compacta, a profound loss of dopamine in the striatum, and the presence of intracytoplasmic inclusions called Lewy bodies, which are mainly composed of a-synuclein and ubiquitin [20].

Like in AD, PD symptoms appear gradually but are unique and dependent on the affected brain subregion. They include difficulties in maintaining balance and in ambulation; tremors; inflexibility/stiffness of the limbs and trunk; and bradykinesia (slowness of movement) [21]. Neuronal damage caused by neurotoxic factors initiated from inflammatory responses by immune activated glia are linked to cognitive and motor deterioration, which contribute to the breakdown of the blood-brain barrier (BBB). This allows leukocytes to enter into the brain serving to speed a neuroinflammatory cascade. Although the causes of both $A D$ and PD remain unknown, patterns of familial inheritance suggest a possible connection involving abnormal protein processing ( $A \beta$ for $A D$ and alpha synuclein for PD) and accumulation [22].

As neurodegenerative diseases, brain tumors are also included in CNS disorders. Brain tumors have a great significance between the CNS diseases and have one of the higher costs per habitant of the neurological disorders (Figure 1). Difference between men and women are reflected in the different statistics for brain tumors (Table 2). Primary brain tumors represent $2 \%$ of all cancers [23] and are a diverse group of tumors with marked differences in etiology, treatment and prognosis [24]. The term "brain tumours" refers to a mixed group of neoplasms originating in intracranial tissues and the meninges with degrees of malignancy ranging from benign to aggressive [25]. Primary brain tumors can be classified into gliomas, the most common adult brain tumors occurring in the brain parenchyma above the tentorium, and medulloblastomas, child or young adult cerebellar tumors occurring below the tentorium [26]. Most of these brain tumors have an unknown etiology and they represent the most devastating and difficult cancer to treat.

Currently, a majority of modern pharmacological therapies provide symptomatic relief to patients with CNS diseases, but are commonly associated with adverse side effects and often do not halt disease progression. Moreover, patients afflicted with complex CNS diseases typically require life-long medication with a marginal improvement in the quality of life [27]. On the one hand, a major limitation for the development of efficacious CNS treatments is the lack of knowledge on the mechanism of neurological diseases. And on the other hand, the currently available therapeutics for these disorders only act to lower its symptoms [28].

\section{Animal models of neurological disorders}

Actually, in vivo techniques are the most reliable techniques for studying and understanding the neurological disease progression as they use living tissue and they examine 


\section{Total costs \\ (million €PPP, 2010)}
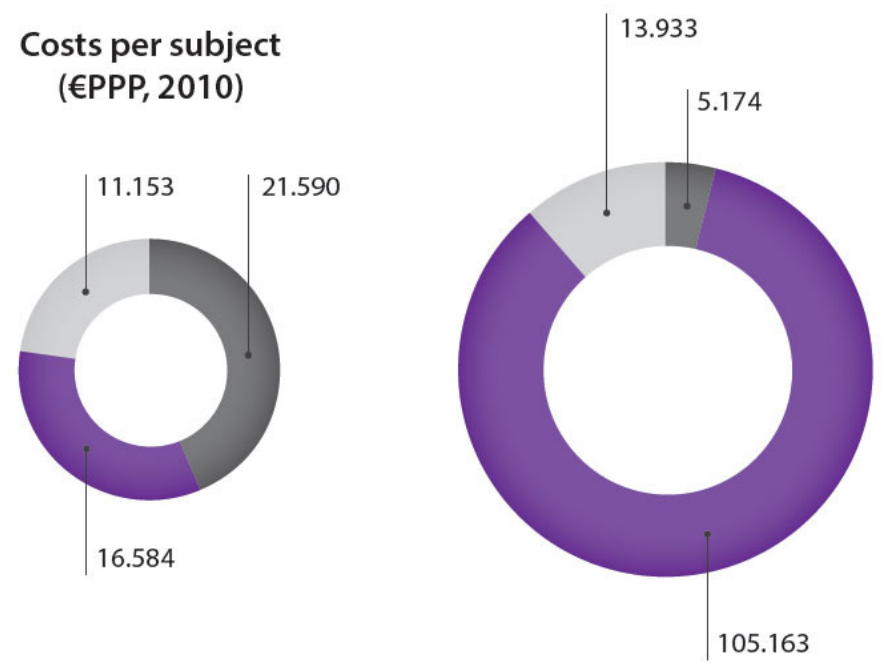

Brain tumor

Dementia

Parkinson

Figure 1. Costs of brain disorders in Europe. CNS diseases have one of the higher costs per habitant.

Table 2. Brain and other central nervous system tumors statistics in Europe. Difference between men and women are reflected in these statistics for brain tumors.

\begin{tabular}{ccccccccccc}
\hline & \multicolumn{3}{c}{ Incidence } & \multicolumn{3}{c}{ Mortality } & \multicolumn{3}{c}{ 5-years prevalence } \\
\hline & Number & $\%$ & ASR(w) & Number & $\%$ & ASR(w) & Number & $\%$ & PROP \\
\hline \multirow{2}{*}{ Men } & 28.942 & 1,7 & 6,2 & 23.312 & 2,4 & 4,6 & 32.846 & 0,8 & 11,2 \\
Women & 25.863 & 1,7 & 4,6 & 19.641 & 2,6 & 3,1 & 27.165 & 0,6 & 8,4 \\
Both & 54.805 & 1,7 & 5,3 & 42.953 & 2,5 & 3,8 & 60.011 & 0,7 & 9,7 \\
\hline
\end{tabular}

the overall effect of the whole body on an experiment. However, drawbacks include the requirement of large numbers of live animals, low throughput, the need for expensive equipment and experimental expertise as well as the highly invasive nature of the studies [29].

Ideally, animal models of neurodegenerative diseases should reproduce the clinical manifestation of the disease, a selective neuronal loss [30]. There are two approaches to produce mouse models of human disease. On the one hand, the genotype-driven approach depends on knowing the gene of interest, and then manipulating this gene in the mouse to create the appropriate model. On the other hand, the phenotype-driven approach, is not gene dependent, but uses standard gene-mapping and cloning techniques to identify the causal genetic change in an interesting phenotype [31].

In AD have been described many experimental models. For example, there are animal models based on the metabolism of the amyloid precursor protein, and other models based on Presenilin or on tau protein [32]. According to PD, animal models of PD can be divided into those using environmental or synthetic neurotoxins and those utilizing the in vivo expression of PD-related mutations [33]. Toxic models represent the classic experimental PD models; they aim to reproduce the pathological and behavioural changes of this human disease in rodents or primates by using pharmacological agents (neurotoxins) that induce the selective degeneration of nigrostriatal neurons [34].

Brain tumor models have been developed in a variety of forms, which can be classified as chemically induced models, xenograft tumor models or models of spontaneous tumor formation in genetically engineered mice and help address issues of utmost importance in drug development: toxicity and in vivo antitumor effectiveness [35]. The establishment of tumors in animals by xenografting tumor material has been highly valuable in the search for mechanisms that determine tumor formation, growth, and progression. In particular, with the advent of immunodeficient animals, important insights have been obtained relating to the growth of human tumors within the CNS [36]. Xenograft 
Domínguez et al. Neuroscience Discovery 2013,

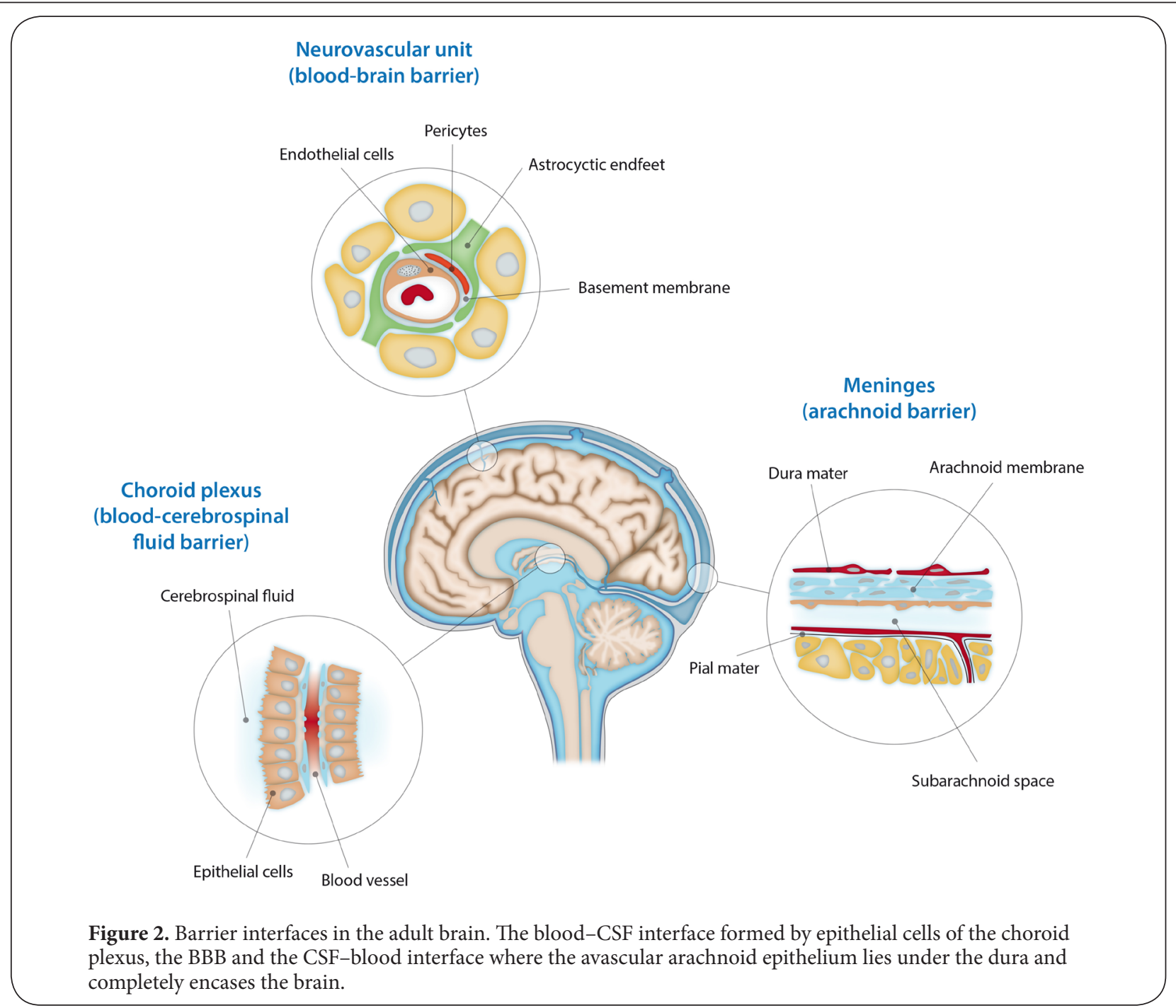

tumors are characterized by synchrony and reproducibility of tumor formation, rapid tumor development, easy tumor visualization and high penetrance [37]. Increased understanding of genomic alterations in primary brain tumors has led to the development of highly characterized genetically engineered mouse models of glioma based on specific genetic alterations observed in human tumors [38]. These mouse models of human cancers are generated by somatic or germline genetic modification strategies [39]. At least in brain tumor modeling, the use of mouse models forming spontaneous tumors is complicated by poor reproducibility, low tumor penetrance, prolonged tumor formation latency, and a need for advanced in vivo imaging techniques.

Preferably animal models of CNS disorders should reproduce all the specific changes to a given disease. Unluckily, most of the models reproduce only certain aspects of the diseases. For this reason they are poorly indicative of the efficacy of neuroprotective substances in humans.

\section{Blood-brain barrier}

Not only understanding the neurological diseases progression, but also discovery and development of CNS drugs is a substantial challenge in the neuropharmaceutical industry, due to the persistent difficulty of delivering drug molecules across the BBB [40].

There are three main interfaces in the brain that protect neurons from blood-borne substances and help to maintain water homeostasis and an appropriate milieu for neuronal function (Figure 2). The blood-CSF interface formed by epithelial cells of the choroid plexus, the BBB and the CSFblood interface where the avascular arachnoid epithelium lies under the dura and completely encases the brain [41]. The BBB has the largest surface area of all three interfaces, creating an extremely high density capillary network throughout the brain parenchyma with a total length of $600-650 \mathrm{~km}$ and a surface area of $20 \mathrm{~m}^{2}$ [42] providing almost every neuron with an individual blood supply [43]. Hence, the BBB is considered to be the primary interface of the brain. 
Domínguez et al. Neuroscience Discovery 2013,

The CNS requires a perfectly regulated environment and homeostasis with characteristics far different from those in the rest of the organism. The main factor maintaining the homeostasis of the CNS is the proper function of the $\mathrm{BBB}$. Under both physiological and pathological conditions, the $\mathrm{BBB}$ isolates and protects nervous tissue of the brain and spinal cord from fluctuations in nutrients, hormones, metabolites, and other blood constituents. It also protects this tissue from the direct influences of many endo- or exogenous compounds circulating in the blood [44]. Therefore, the BBB forms the anatomical and physiological interface separating the brain from the blood and protecting the microenvironment of the CNS via controlling the passage of endogenous substances and xenobiotics into and out of the CNS [45].

\section{Structural components of BBB: neurovascular unit} The BBB is composed of a microvascular endothelium, astrocytes, basement membrane, pericytes and neurons that are in physical proximity to the endothelium. All these elements are part of the functional neurovascular unit.

Brain microvascular endothelial cells (BMECs) perform essential biological functions, including barrier, transport of micronutrients and macronutrients, receptor-mediated signaling, leukocyte trafficking and osmoregulation [46]. BMECs form a very thin but very effective barrier between blood and brain parenchyma. Brain micro-vessels are phenotypically unique compared to vessels in the periphery. They have somewhat smaller diameter, thinner wall and higher mitochondrial density than vessels in other organs [47]. BMECs possess also an enzymatic function, capable of metabolizing drug and nutrients. These enzymes include $\gamma$-glutamyl transpeptidase and alkaline phosphatase present at the luminal endothelium. Furthermore, BMECs express several drug efflux transporters mainly present on the luminal membrane surface, including P-gp, multidrug resistance-associated proteins, GluT1 and LAT1 [48]. The basement membrane of the BBB endothelial cells is common with that of the perivascular astrocytic endfeet and that of the pericytes, which are completely surrounded by a basement membrane, making the endothelial cells tightly integrated into the brain parenchyma [49].

Astrocytes, like neurons, derive from the ectoderm of the neural tube. BMECs are enveloped by astrocytes endfeet specialized processes sent by astrocytes, where they form rosette-like structures [50]. Astrocytes and endothelial cells influence each other's structure; their interactions induce and modulate the development of the BBB and unique endothelial cell phenotype. Interaction of astrocytes with BMECs greatly enhances endothelial cell tight junctions (TJs) and reduces gap junctional area. This interaction increases the number of astrocytic membrane particle assemblies and astrocyte density [51].

In an identical manner as capillaries, venules, and arterioles that wrap around the endothelial cells, pericytes are cells of microvessels. They are separated from BMECs by the basement membrane, but gap junctions provide contact spots. There is evidence that pericytes are able to mimic astrocyte ability to induce BBB "tightness." These evidences support the hypothesis that pericytes play an important role in maintaining the structural integrity of the BBB [52].

\section{Structural integrity of BBB: junctional complexes}

The most important factors responsible for BBB impermeability are the junctional complexes existing between the ECs of brain microvessels. TJs exist between the ECs and encircle the cells like a continuous belt. The TJs consist of three integral membrane proteins (occludin, claudin and junctional adhesion molecules (JAM)), which are linked to different cytoplasmic accessory proteins, including the zonula occludens (ZO) proteins ZO-1, ZO- 2, ZO-3 and cingulin. Cytoplasmic proteins link membrane proteins to actin, which is the primary cytoskeleton protein for the maintenance of structural and functional integrity of the endothelium [53].

Functionally, TJs work in several ways. They constitute the frontier for protein and lipid diffusion across the membranes and confer to the ECs polarity, which is manifested by a non-uniform distribution of a number of transporters between the luminal and abluminal membranes. Due to complete fusion, they also seal the paracellular way to force transport of substances through the membranes and cytosol [54]. TJs are characterized by high electrical resistance. The integrity of the TJs assembly determines the paracellular permeability of water-soluble molecules across the BBB.

The first integral membrane protein to be discovered was the occludin. The cytoplasmic domains of occludin are directly associated with ZO proteins. It seems that occludin function is regulatory and may influence paracellular transport [55]. Occludin content is much lower in endothelial cells of non-CNS origin, suggesting that occludin is actively involved in BBB function. It has been shown that high levels of occludin ensure high electrical resistance (tightness) of the epithelial cell monolayers [56].

The major components of TJs are claudins. The claudin from one endothelial cell connects with an analogous claudin from an adjacent endothelial cell to create the "primary closure" of the TJs, and the carboxylic end of each protein links it to cytoplasmic ZO-1, ZO-2, or ZO-3. At the BBB, claudin-3 and claudin-5 appear to be responsible for the low paracellular [57].

The JAMs are transmembrane proteins belong to the immunoglobulin superfamily [58]. It mediates the early attachment of adjacent cell membranes via homophilic interactions of a single membrane-spanning chain with a large extracellular domain [59]. Their function in the mature BBB is still largely unknown [60]. The expression of JAMs at the human $\mathrm{BBB}$ remains to be explored. 


\section{Regulation of Paracellular Permeability}

The mechanisms affecting the brain uptake of drugs include passive diffusion, carrier-mediated transport, receptormediated transport and active efflux transport.

The independent movement and energy of drug molecules along a concentration gradient are involved by passive diffusion. The rate of diffusion is directly proportional to the concentration gradient of the solutes across the membrane. Passive diffusion can occur either between the cells (paracellular) or through the cells (transcellular), depending on the physicochemical properties of the solutes. Since tight junctions block the paracellular route across the $B B B$, only solutes which are able to penetrate through the endothelial cell membrane are able to cross the BBB via passive diffusion [61]. Therefore, only a few drug molecules can efficiently cross the BBB by passive diffusion.

Carrier-mediated transport proteins move small hydrophilic molecules such as amino acids, nucleosides or glucose. These transporters systems are expressed on both the luminal and abluminal membranes of the capillary endothelium, catalysing the bidirectional movement between blood and brain transporting solutes solutes either from brain to blood or from blood to brain. All of these molecules access different specialized transporter proteins, which are stereospecific and mediate solute transport in the order of milliseconds. All of them use chemical and/or electrical gradients to move molecules across cell membranes. Examples include the GLUT1 glucose transporters, MCT1 lactate transporters, LAT1 large neutral amino-acid transporters or CNT2 adenosine transporters [62]

Brain uptake of large molecules such as peptides and proteins is limited due to the BBB. The endocytotic activity of BMECs is lower than in the peripheral endothelial cells [63]. However, the brain uptake of some large molecular weight molecules is necessary to ensure the normal function of the brain. Therefore, some peptides and proteins gain their access into the CNS via receptor-mediated transport, such as the insulin receptor, the transferrin receptor or the leptin receptor.

Active efflux transporters have a major impact on the drug systemic pharmacokinetics. The lower brain uptake of lipophilic solutes is often due to active efflux proteins [64] The efflux transporters have a broad range of substrates, and strong substrates of $B B B$ efflux transporters do not pass the $B B B$ to a functionally relevant extent, which restricts their therapeutic effects to the periphery. $A B C$ transporters comprise one of the largest protein families, and they are crucial for a number of biomedical aspects like drug transport and resistance to cancer and xenobiotics. These transporters are membrane proteins consisting of many domains that use ATP-bound energy for the transport of solutes across the cell membrane in all mammals [65]. Members of this family include P-gp, ABCC family and breast cancer resistance protein (BCRP). These proteins have a broad substrate specificity including organic cations, weak organic bases, some organic anions and some uncharged compounds which compromise a wide variety of drugs, such as anticancer drugs, anti-HIV drug and glutathione, glucuronide, carcinogens and dietary toxins [66-69].

Due to the BBB composition and its specific regulation of paracellular integrity described above, the BBB is now recognized as the major obstacle to the treatment of most neurological disorders, as it hinders the delivery of many potentially important therapeutic and diagnostic substances to the CNS [70].

A successful CNS drug disposition is hindered by the high degree of protection afforded to the brain via the BBB [71], CNS drug penetration is modulated by BBB permeability and active transport at the BBB. Analysis of currently approved therapies shows that all products depend on the molecular properties of the drug to penetrate the BBB [72]. To facilitate drug delivery, several approaches to overcome the $B B B$ have been investigated [73].

\section{Delivery systems across the bbb to treat brain diseases}

Generally, only low molecular weight, lipid-soluble molecules and a few peptides and nutrients can cross this barrier to any significant extent, either by passive diffusion or using specific transport mechanisms [74]. To overcome the BBB restricting CNS drug delivery of potential therapeutic agents and in response to the insufficiency in conventional delivery mechanisms, extensive research efforts have recently focused on the development of new drug delivery strategies to more effectively deliver drug molecules to the CNS [75].

To bypass the BBB and to deliver therapeutics into the brain, two different approaches are currently used; invasive and non-invasive methods including BBB disruption, nasal delivery or colloidal drug carriers.

\section{Invasive methods}

The drugs can be administered directly into the brain tissue. There are some physical based techniques that include intracerebroventricular injection into the cerebrospinal fluid, intraparenchymal infusion by convection-enhanced delivery, intracerebral implantation and the BBB integrity disruption.

Disruption of the BBB can open access of the brain to components in the blood by making the tight junction between the endothelial cells of the brain capillaries leaky [76]. The idea behind this approach was to break down the barrier temporarily by an osmotic disruption [77]. The disruption could also be broken down by MRI-guided focused ultrasound BBB disruption technique [78]. These methods allow the delivery of therapeutic agents in patients with CNS disorders. However, this approach also causes several undesirable side effects in humans, including physiological stress, transient increase in intracranial pressure, and unwanted delivery of therapeutic agents 
Domínguez et al. Neuroscience Discovery 2013,

to normal brain tissue [79].

Other strategies to overcome the BBB that have been used extensively in clinical trials are the direct administration of drugs by intraventricular and intracerebral routes. CNS local delivery includes intracerebroventricular injection (ICV) into the cerebrospinal fluid, where the drug enters the brain parenchyma following transport across the BBB and the convection enhanced delivery (CED), an intraparenchymal infusion of the drug solution into the brain parenchyma by a catheter. This method involves the stereotactically guided insertion of a small-caliber catheter into the brain parenchyma. Through this catheter, infusate is actively pumped into the brain parenchyma and penetrates in the interstitial space [80]. The infusion is continued for several days before catheters remove. Both neurosurgical based delivery approaches have limitations. For example, the diffusion of the drug by ICV delivery in the brain parenchyma is very low. Besides, an insufficient concentration of drug may reach the target site, secreted interstitial fluid flow works against diffusive drug penetration and the high turnover rate of the CSF continuously clears injected drug back into the blood apart from the surgical intervention required [81]. Likewise, in the CED strategy, some areas of the brain are difficult to saturate fully with infusate, particularly infiltrated tissues surrounding a cavity. Proper drug delivery depends on the placement of catheters based on knowledge of these factors [82].

CNS local delivery also includes intracerebral implants. The advantages of implantable polymer systems have recently prompted several teams to study their use in CNS pathologies. Different CNS diseases principally brain tumours and neurodegenerative disorders such as PD and Huntington's diseases can be treated with intracranially administered controlled drug delivery systems [83]. The efficiency of various devices has been investigated in animal models and some systems have also been subjected to clinical trials [84]. But the efficacy of this method is still unclear, since the injection site has to be very precisely mapped in order to get efficacy and overcome the problem associated with diffusion of drugs in the brain parenchyma.

The approaches above described are relatively costly, requiring anesthesia and hospitalization. Likewise, these neurosurgical based delivery approaches have several limitations in the drug administration and diffusion into the brain. The distribution in the brain by diffusion decreases exponentially with distance and these methods have to be very precisely mapped to get efficacy. So, although invasive methods of administration have been used to overcome the $\mathrm{BBB}$, these methods are not really practical for use due to several reasons, including convenience, safety and cost.

\section{Non-invasive methods}

A variety of non-invasive brain drug delivery methods have been investigated, these methods make use of the brain blood vessel network to gain widespread drug distribution. Noninvasive techniques of delivery may be of a chemical or biological nature. Such methods usually rely upon drug manipulations which may include alterations as prodrugs, lipophilic analogues, chemical drug delivery, carrier-mediated drug delivery, receptor/vector mediated drug delivery etc. Intranasal drug delivery which primarily exploits the olfactory and trigeminal neuronal pathways has also gained a recent reappraisal as a potential noninvasive approach [85].

\section{Intranasal administration}

The use of intranasal administration (IN) to target therapeutics to the CNS has many benefits in the treatment of neurologic disorders. IN drug delivery has been investigated due to the direct access from the nasal cavity to the CNS via the olfactory epithelium and/or the trigeminal nerve system [86]. It offers rapid absorption to the systemic blood avoiding first pass metabolism in the gut wall and the liver. This route of administration has been shown to present a safe and acceptable alternative to parenteral administration of specific drugs [87].

Taking into account that drugs absorbed via the olfactory route do not have to cross the BBB, substances could possibly be delivered to the CNS directly. This can be advantageous for delivery of CNS therapeutics, including those that can cross the BBB upon systemic administration. CNS therapeutics do not necessarily need to be modified for IN delivery, and delivery of therapeutics to the CNS is rapid, occurring within minutes [88].

\section{Systemic delivery / Transported mediated delivery}

Peptides and small molecules may use specific transporters expressed on the luminal and basolateral side of the endothelial cells forming the BBB to cross into the brain [89]. Carrier transporters are stereospecific and small, therefore, only a limited number of substances can potentially be delivered via these transporters. As mentioned previously, the $B B B$ contains several efflux transporters (ATP-binding cassette, $A B C$ ), which expel a multiplicity of drugs from the CNS. Various strategies have emerged in order to avoid the activity of these efflux transporters: either by developing specific inhibitors for the efflux transporters, thus giving their substrates a greater access to the CNS or by attempting to design analogues of drugs with known efficacy but with poor BBB penetration due to $\mathrm{ABC}$ transporter activity, which will no longer have a reactivity with the efflux transporters [90]. P-glycoprotein (P-gp) is one of the most studied active efflux transporters. Inhibition of the P-gp functions may improve brain permeation as many chemotherapeutic drugs were reported to P-gp substrates.

Large molecules which are necessary for the normal function of the brain are also delivered by specific receptors, via receptor-mediated transcytosis. These receptors are highly expressed on the endothelial cells forming the BBB. These include the insulin receptor, transferrin receptor, LDL 
receptor and its related protein, and others [91]. Over the last decade, there have been significant developments in the area of receptor transporters. The carriers should be conjugated with a ligand able to target a receptor transporter [92].

Finally, another systematic delivery is the use of cellpenetrating peptides which are able to translocate across biological membranes, and to assist the transport of various substances across these biological barriers. Peptide mediated BBB penetration has thus been widely exploited. A number of peptides (eg., TAT, angiopep-2) were tested to identify a more effective BBB penetrating peptide [93] Several cell-penetrating peptides, which appear to enter cells with alacrity, have been developed recently. At present, little is known about the mechanism by which these peptides can cross the cell membrane.

\section{Colloidal drug carriers}

In general, colloidal drug carriers include micelles, emulsions, liposomes and nanoparticles (nanospheres and nanocapsules). It is noteworthy that only liposomes and nanoparticles have been largely exploited for brain drug delivery because the methods of preparation are generally simple and easy to scale-up [94].

Liposomes and nanoparticles are large and complex constructs which can be made from a variety of chemical constituents and may range up to $200 \mathrm{~nm}$ in diameter. Relatively large amounts of drug or agent can be incorporated into these structures, providing the possibility for significant delivery to the CNS. The surface of the liposome or nanoparticle can be modified and groups can be attached so that the construct can be targeted to the CNS via specific BBB mechanisms [95].

The aim of using colloidal carriers is generally, to increase the specificity towards cells or tissues, to improve the bioavailability of drugs by increasing their diffusion through biological membranes and/or to protect them against enzyme inactivation. Moreover, the colloidal systems allow access of non-transportable drugs across the BBB by masking their physicochemical characteristics through their encapsulation in these systems [86].

Polymeric micelles as drug delivery systems are formed by amphiphilic copolymers having an A-B diblock structure with $A$, the hydrophilic (shell) and B, the hydrophobic (core) polymers. The polymeric micelles are thermodynamically and kinetically stable in aqueous media. The narrow size range is similar to that of viruses and lipoproteins [97]. It has also been suggested that liposomes can enhance drug delivery to the brain across the BBB. Liposomes are small artificial vesicles that form a globular shape that consists of two major components: an aqueous core and a surrounding phospholipid bilayer membrane. The aqueous core provides an inner compartment in which a cargo, such as a watersoluble drug, can be carried. The phospholipid bilayer membrane provides a protective coating that insulates the contents of the inner core from release of contents at unintended sites as well as from degradation [98].

Other colloidal drug carriers are the polymeric nanoparticles. Nanoparticles (NPs) are solid colloidal matrixlike particles made of polymers or lipids. Compared with other colloidal carriers, polymeric NPs present a higher stability in contact with the biological fluids. At the same time, their polymeric nature permits the attainment of the desired properties such as controlled and sustained drug release [99] Their main advantages over liposomes are the low number of excipients used in their formulations, the simple procedures for preparation, a high physical stability, and the possibility of sustained drug release that may be suitable in the treatment of chronic diseases [100].

Polymeric NPs were the first polymeric nanocarrier studied for drug delivery devices; they were prepared from a block of polymeric material giving the material an increased blood circulation time and a reduced phagocytic uptake [101]. Biodegradable polymers were then incorporated to maximise the tissue compatibility and minimise the toxicity of the material [102]. Another important type of nanoparticle is the nanotube, which is a hollow cylindrical molecule usually made of a single element. Carbon nanotubes are essentially grapheme sheets which are rolled up to produce perfect cylinders. Chemically, this kind of nanotubes is the most interesting option among all the materials considered for the use as nanocarriers, since they give you a degree of control that is not possible with other materials as almost every carbon atom can be functionalized [103].

Improving new NPs like iron oxide nanoparticles, gold nanoparticles or quantum dots (nanocrystals). The main uses of NPs are therapy and imaging for diagnosis. Imaging is a relatively new discipline that uses probes known as biomarkers to measure biological processes at a molecular level, allowing visualization of events in a living system without causing any damage. This technique is useful in the diagnosis of cancer, as well as other neurological and cardiovascular diseases. The targeting ability of nanoparticles provides them with a number of advantages compared with conventional contrast agents and may provide them the ability to more sensitively detect a number of disease entities [104].

\section{Conclusions}

In summary, brain disorders are currently the core health challenge. The treatment of CNS diseases is particularly difficult since the BBB restricts the access of many compounds to their CNS targets. Accordingly, identifying brain delivery strategies for new therapeutics has become essential. For this reason, efforts are underway to develop strategies increasing the BBB permeability of CNS drugs. In order to assess the drug ability for entering the brain, BBB models that mimic human CNS diseases conditions have been developed. However, there is a need for further optimization of drug design and development of CNS 
Domínguez et al. Neuroscience Discovery 2013,

http://www.hoajonline.com/journals/pdf/2052-6946-1-3.pdf

therapeutics with enhanced activity and improved BBB permeability.

\section{List of abbreviations}

ABC: ATP-binding cassette

$A D$ : Alzheimer's disease

BBB: Blood-brain barrier

BCRP: Breast cancer resistance protein

BMECs: Brain microvascular endothelial cells

CAMP: cyclic Adenosine monophosphate

CED: Convection enhanced delivery

CNS: Central nervous system

ICV: Intracerebroventricular injection

IN: intranasal administration

JAM: Junctional adhesion molecules

MDR: multidrug resistance

MRPs: Multidrug resistance-associated proteins

NPs: Nanoparticles

PD: Parkinson's disease

P-gp: P-glycoprotein

TEER: Transendothelial electrical resistance

TJs: Tight junctions

ZO: Zonula occludens

\section{Competing interests}

The authors declare that they have no competing interests.

\section{Authors' contributions}

Alazne Domínguez participated in the design of the work and performed the draft of the manuscript; Antonia Alvarez and Enrique Hilario retrieved conceptual information; Blanca Suarez-Merino carried out a critical revision to structure the content intellectually and Felipe Goñi-de-Cerio took part in the concept of the work and approved the final version in order to be published. All authors read and approved the final manuscript.

\section{Acknowledgement}

We are thankful to Oscar Larrañeta from Larrama Creativa for his logistic support in designing the included figures. We also owe our thanks to lzaskun Amann for providing the necessary opinion regarding the overall structure building of this review.

\section{Publication history}

Editor: Parminder J. S. Vig, University of Mississippi Medical Center, USA.

EIC: Tadanori Tomita, Northwestern University, Feinberg School of Medicine, USA.

Received: 29-Apr-2013 Revised: 10-Jun-2013

Accepted: 20-Jun-13 Published: 25-Jun-2013

\section{References}

1. Kandel ER and Squire LR: Neuroscience: breaking down scientific barriers to the study of brain and mind. Science 2000, 290:111320. | Article | PubMed

2. Hyman S, Chisholm D, Kessler R, Patel V and Whiteford HA: Mental disorders in disease control priorities in developing countries. In: Jamison DT, Breman JG, Measham AR, Alleyne G, Claeson M, Evans DB (Eds.). Disease control priorities in developing countries 2006, 605-25. I Book

3. Nathan DG, Fontanarosa PB and Wilson JD: Opportunities for medical research in the 21st century. JAMA 2001, 285:533-4. | Article I PubMed

4. World health organization: Neurology and public health. | Website
5. Lopez AD, Mathers CD, Ezzati M, Jamison DT and Murray CJL: Measuring the Global Burden of Disease and Risk Factors, 19902001. In: Lopez AD, Mathers CD, Ezzati M, Jamison DT and Murray CJL (Eds.), Global Burden of Disease and Risk Factors 2006. Chapter 1. | Book

6. Gustavsson A, Svensson M, Jacobi F, Allgulander C, Alonso J, Beghi E, Dodel R, Ekman M, Faravelli C, Fratiglioni L, Gannon B, Jones DH, Jennum $P$, Jordanova A, Jonsson L, Karampampa K, Knapp M, Kobelt G, Kurth T, Lieb R, Linde M, Ljungcrantz C, Maercker A, Melin B, Moscarelli M, Musayev A, Norwood F, Preisig M, Pugliatti M, Rehm J, Salvador-Carulla L, Schlehofer B, Simon R, Steinhausen HC, Stovner LJ, Vallat JM, Van den Bergh P, van Os J, Vos P, Xu W, Wittchen HU, Jonsson B and Olesen J: Cost of disorders of the brain in Europe 2010. Eur Neuropsychopharmacol 2011, 21:718-79. | Article | PubMed

7. Menken M, Munsat TL and Toole JF: The global burden of disease study: implications for neurology. Arch Neurol 2000, 57:418-20. | Article | PubMed

8. Wittchen HU, Jacobi F, Rehm J, Gustavsson A, Svensson M, Jonsson B, Olesen J, Allgulander C, Alonso J, Faravelli C, Fratiglioni L, Jennum P, Lieb R, Maercker A, van Os J, Preisig M, Salvador-Carulla L, Simon R and Steinhausen HC: The size and burden of mental disorders and other disorders of the brain in Europe 2010. Eur Neuropsychopharmacol 2011, 21:655-79. | Article | PubMed

9. von Campenhausen S, Bornschein B, Wick R, Botzel K, Sampaio C, Poewe W, Oertel W, Siebert U, Berger K and Dodel R: Prevalence and incidence of Parkinson's disease in Europe. Eur Neuropsychopharmacol 2005, 15:473-90. | Article | PubMed

10. Vangilder RL, Rosen CL, Barr TL and Huber JD: Targeting the neurovascular unit for treatment of neurological disorders. Pharmacol Ther 2011, 130:239-47. | Article | PubMed Abstract | PubMed Full Text

11. Loenneke JP and Pujol TJ: Sarcopenia: An emphasis on occlusion training and dietary protein. Hippokratia 2011, 15:132-7. | PubMed Abstract | PubMed Full Text

12. A/CONF.197/9. Report of the Second World Assembly on Ageing. Madrid, 8-12 April 2002, United Nations, New York. | Pdf

13. Prince $M$, Bryce $R$, Albanese $E$, Wimo A, Ribeiro $W$ and Ferri CP: The global prevalence of dementia: a systematic review and metaanalysis. Alzheimers Dement 2013, 9:63-75. | Article | PubMed

14. Hung CW, Chen YC, Hsieh WL, Chiou SH and Kao CL: Ageing and neurodegenerative diseases. Ageing Res Rev 2010, 9 Suppl 1:S36-46. | Article | PubMed

15. Devous MD, Sr.: Functional brain imaging in the dementias: role in early detection, differential diagnosis, and longitudinal studies. Eur J Nucl Med Mol Imaging 2002, 29:1685-96. | Article | PubMed

16. Kabanov AV and Gendelman HE: Nanomedicine in the diagnosis and therapy of neurodegenerative disorders. Prog Polym Sci 2007, 32:1054-1082. | Article | PubMed Abstract | PubMed Full Text

17. Alzheimer's Society. Drug treatments for Alzheimer's disease. | Website

18. Lobo A, Launer LJ, Fratiglioni L, Andersen K, Di Carlo A, Breteler MM, Copeland JR, Dartigues JF, Jagger C, Martinez-Lage J, Soininen H and Hofman A: Prevalence of dementia and major subtypes in Europe: A collaborative study of population-based cohorts. Neurologic Diseases in the Elderly Research Group. Neurology 2000, 54:S4-9. | Article I PubMed

19. Reynish E, Fratiglioni L, Prince M, Bickel H, Kiejna A and Georges J: EuroCoDe: Report of WP 7 2006. Prevalence of Dementia in Europe. 2009. I Pdf

20. Blesa J, Phani S, Jackson-Lewis V and Przedborski S: Classic and new animal models of Parkinson's disease. J Biomed Biotechnol 2012, 2012:845618. | Article | PubMed Abstract | PubMed Full Text

21. Blandini F and Armentero MT: Animal models of Parkinson's disease. FEBS Journal 2012, 279: 1156-66. | Article

22. Berghmans N, Heremans H, Li S, Martens E, Matthys P, Sorokin L, Van Damme J and Opdenakker G: Rescue from acute neuroinflammation by pharmacological chemokine-mediated deviation of leukocytes. J Neuroinflammation 2012, 9:243. | Article | PubMed Abstract | PubMed Full Text

23. Ferlay J, Parkin DM and Steliarova-Foucher E: Estimates of cancer incidence and mortality in Europe in 2008. Eur J Cancer 2010, 46:765-81. | Article | PubMed 
Domínguez et al. Neuroscience Discovery 2013,

24. Bondy ML, Scheurer ME, Malmer B, Barnholtz-Sloan JS, Davis FG, II'yasova D, Kruchko C, McCarthy BJ, Rajaraman P, Schwartzbaum JA, Sadetzki S, Schlehofer B, Tihan T, Wiemels JL, Wrensch M and Buffler PA: Brain tumor epidemiology: consensus from the Brain Tumor Epidemiology Consortium. Cancer 2008, 113:1953-68. | Article | PubMed Abstract | PubMed Full Text

25. McKinney PA: Brain tumours: incidence, survival, and aetiology. J Neurol Neurosurg Psychiatry 2004, 75 Suppl 2:ii12-7. | Article | PubMed Abstract | PubMed Full Text

26. Lassman $A B$ and Holland EC: Central nervous system tumors. In: Holland (Ed.) Mouse models of human cancers, 2004. I Article

27. Olesen J, Gustavsson A, Svensson M, Wittchen HU and Jonsson B: The economic cost of brain disorders in Europe. Eur J Neurol 2012, 19:155-62. | Article | PubMed

28. Palmer AM: The role of the blood-CNS barrier in CNS disorders and their treatment. Neurobiol Dis 2010, 37:3-12. | Article | PubMed

29. Chesselet MF and Carmichael ST: Animal models of neurological disorders. Neurotherapeutics 2012, 9:241-4. | Article | PubMed Abstract | PubMed Full Text

30. Hirsch EC: Animal models in neurodegenerative diseases. J Neura Transm Supp/ 2007, 87-90. | Article | PubMed

31. Hafezparast M, Ahmad-Annuar A, Wood NW, Tabrizi SJ and Fisher EM: Mouse models for neurological disease. Lancet Neurol 2002, 1:215-24. | Article I PubMed

32. Manzano S, Gonzalez J, Marcos A, Payno M, Villanueva C and Matias-Guiu J: [Experimental models in Alzheimer's disease]. Neurologia 2009, 24:255-62. | Article | PubMed

33. Blesa J, Phani S, Jackson-Lewis $\mathrm{V}$ and Przedborski S: Classic and new animal models of Parkinson's disease. J Biomed Biotechnol 2012, 2012:845618. | Article | PubMed Abstract | PubMed Full Text

34. Blandini F and Armentero MT: Animal models of Parkinson's disease. FEBS J 2012, 279:1156-66. | Article | PubMed

35. Fomchenko El and Holland EC: Mouse models of brain tumors and their applications in preclinical trials. Clin Cancer Res 2006, 12:5288-97. | Article | PubMed

36. Huszthy PC, Daphu I, Niclou SP, Stieber D, Nigro JM, Sakariassen PO, Miletic $\mathrm{H}$, Thorsen $\mathrm{F}$ and Bjerkvig $\mathrm{R}$ : In vivo models of primary brain tumors: pitfalls and perspectives. Neuro Oncol 2012, 14:979-93. I Article | PubMed Abstract | PubMed Full Text

37. Finkelstein SD, Black P, Nowak TP, Hand CM, Christensen S and Finch PW: Histological characteristics and expression of acidic and basic fibroblast growth factor genes in intracerebral xenogeneic transplants of human glioma cells. Neurosurgery 1994, 34:136-43. | Article | PubMed

38. Huse JT and Holland EC: Genetically engineered mouse models of brain cancer and the promise of preclinical testing. Brain Pathol 2009, 19:132-433. | Article | PubMed Abstract | PubMed Full Text

39. Holland EC: Mouse models of human cancer as tools in drug development. Cancer Cell 2004, 6:197-8. | Article | PubMed

40. Avdeef A: How well can in vitro brain microcapillary endothelial cell models predict rodent in vivo blood-brain barrier permeability? Eur J Pharm Sci 2011, 43:109-24. | Article | PubMed

41. Saunders NR, Ek CJ, Habgood MD and Dziegielewska KM: Barriers in the brain: a renaissance? Trends Neurosci 2008, 31:279-86. | Article I PubMed

42. Pardridge WM: Molecular biology of the blood-brain barrier. Mol Biotechnol 2005, 30:57-70. | Article | PubMed

43. Reichel A: Addressing central nervous system (CNS) penetration in drug discovery: basics and implications of the evolving new concept. Chem Biodivers 2009, 6:2030-49. | Article | PubMed

44. Bernacki J, Dobrowolska A, Nierwinska K and Malecki A: Physiology and pharmacological role of the blood-brain barrier. Pharmacol Rep 2008, 60:600-22. | Pdf | PubMed

45. Pardridge WM: Blood-brain barrier delivery. Drug Discov Today 2007, 12:54-61. | Article | PubMed

46. Persidsky Y, Ramirez SH, Haorah J and Kanmogne GD: Blood-brain barrier: structural components and function under physiologic and pathologic conditions. J Neuroimmune Pharmacol 2006, 1:223-36. | Article I PubMed

47. Misra A, Ganesh S, Shahiwala A and Shah SP: Drug delivery to the central nervous system: a review. J Pharm Pharm Sci 2003, 6:25273. | Article | PubMed

48. Abbott NJ: Dynamics of CNS barriers: evolution, differentiation, and modulation. Cell Mol Neurobiol 2005, 25:5-23. | Article | PubMed

49. Goldstein GW and Betz AL: Recent advances in understanding brain capillary function. Ann Neurol 1983, 14:389-95. | Article | PubMed

50. Kacem K, Lacombe P, Seylaz J and Bonvento G: Structural organization of the perivascular astrocyte endfeet and their relationship with the endothelial glucose transporter: a confocal microscopy study. Glia 1998, 23:1-10. | Article | PubMed

51. Tao-Cheng JH and Brightman MW: Development of membrane interactions between brain endothelial cells and astrocytes in vitro. Int J Dev Neurosci 1988, 6:25-37. | Article | PubMed

52. Lai $\mathrm{CH}$ and Kuo $\mathrm{KH}$ : The critical component to establish in vitro BBB model: Pericyte. Brain Res Brain Res Rev 2005, 50:258-65. | Article I PubMed

53. Ballabh $P$, Braun $A$ and Nedergaard $M$ : The blood-brain barrier: an overview: structure, regulation, and clinical implications. Neurobiol Dis 2004, 16:1-13. | Article | PubMed

54. Grieb P, Forster RE, Strome D, Goodwin CW and Pape PC: $\mathbf{O 2}$ exchange between blood and brain tissues studied with 1802 indicator-dilution technique. J Appl Physiol 1985, 58:1929-41. | Article | PubMed

55. Hirase T, Staddon JM, Saitou M, Ando-Akatsuka Y, Itoh M, Furuse M, Fujimoto K, Tsukita S and Rubin LL: Occludin as a possible determinant of tight junction permeability in endothelial cells. $J$ Cell Sci 1997, 110 ( Pt 14):1603-13. | Article | PubMed

56. Wong $V$ and Gumbiner BM: A synthetic peptide corresponding to the extracellular domain of occludin perturbs the tight junction permeability barrier. J Cell Biol 1997, 136:399-409. | Article | PubMed Abstract | PubMed Full Text

57. Liebner S, Fischmann A, Rascher G, Duffner F, Grote EH, Kalbacher $\mathrm{H}$ and Wolburg $\mathrm{H}$ : Claudin-1 and claudin-5 expression and tight junction morphology are altered in blood vessels of human glioblastoma multiforme. Acta Neuropathol 2000, 100:323-31. | Article | PubMed

58. Aurrand-Lions $M$, Johnson-Leger $C$, Wong $C$, Du Pasquier $L$ and Imhof BA: Heterogeneity of endothelial junctions is reflected by differential expression and specific subcellular localization of the three JAM family members. Blood 2001, 98:3699-707. | Article | PubMed

59. Del Maschio A, De Luigi A, Martin-Padura I, Brockhaus M, Bartfai T, Fruscella P, Adorini L, Martino G, Furlan R, De Simoni MG and Dejana $\mathrm{E}$ : Leukocyte recruitment in the cerebrospinal fluid of mice with experimental meningitis is inhibited by an antibody to junctional adhesion molecule (JAM). J Exp Med 1999, 190:1351-6. | Article | PubMed Abstract | PubMed Full Text

60. Hawkins BT and Davis TP: The blood-brain barrier/neurovascular unit in health and disease. Pharmacol Rev 2005, 57:173-85. | Article | PubMed

61. Tsuji A: Small molecular drug transfer across the blood-brain barrier via carrier-mediated transport systems. NeuroRx 2005, 2:54-62. | Article | PubMed Abstract | PubMed Full Text

62. Pardridge WM: Drug and gene targeting to the brain with molecular Trojan horses. Nat Rev Drug Discov 2002, 1:131-9. | $\underline{\text { Article I PubMed }}$

63. Rubin LL and Staddon JM: The cell biology of the blood-brain barrier. Annu Rev Neurosci 1999, 22:11-28. | Article | PubMed

64. Loscher $\mathrm{W}$ and Potschka $\mathrm{H}$ : Blood-brain barrier active efflux transporters: ATP-binding cassette gene family. NeuroRx 2005, 2:86-98. | Article | PubMed Abstract | PubMed Full Text

65. Jones PM and George AM: The ABC transporter structure and mechanism: perspectives on recent research. Cell Mol Life Sci 2004, 61:682-99. | Article | PubMed

66. Zhang Y, Schuetz JD, Elmquist WF and Miller DW: Plasma membrane localization of multidrug resistance-associated protein homologs in brain capillary endothelial cells. J Pharmacol Exp Ther 2004, 311:449-55. | Article | PubMed

67. Cooray HC, Blackmore CG, Maskell L and Barrand MA: Localisation of breast cancer resistance protein in microvessel endothelium of human brain. Neuroreport 2002, 13:2059-63. | Article | PubMed

68. Schinkel $\mathrm{AH}$ and Jonker JW: Mammalian drug efflux transporters of the ATP binding cassette (ABC) family: an overview. Adv Drug Deliv Rev 2003, 55:3-29. | Article | PubMed

69. Doyle L and Ross DD: Multidrug resistance mediated by the breast 
Domínguez et al. Neuroscience Discovery 2013,

http://www.hoajonline.com/journals/pdf/2052-6946-1-3.pdf

cancer resistance protein BCRP (ABCG2). Oncogene 2003, 22:734058. | Article | PubMed

70. Neuwelt E, Abbott NJ, Abrey L, Banks WA, Blakley B, Davis T, Engelhardt B, Grammas P, Nedergaard M, Nutt J, Pardridge W, Rosenberg GA, Smith Q and Drewes LR: Strategies to advance translational research into brain barriers. Lancet Neurol 2008, 7:8496. | Article | PubMed

71. Abbott NJ: Blood-brain barrier structure and function and the challenges for CNS drug delivery. J Inherit Metab Dis 2013, 36:43749. | Article | PubMed

72. Jeffrey $P$ and Summerfield $S$ : Assessment of the blood-brain barrier in CNS drug discovery. Neurobiol Dis 2010, 37:33-7. | Article | PubMed

73. DiNunzio JC and Williams RO, 3rd: CNS disorders--current treatment options and the prospects for advanced therapies. Drug Dev Ind Pharm 2008, 34:1141-67. | Article | PubMed

74. Greig NH: Optimizing drug delivery to brain tumors. Cancer Treat Rev 1987, 14:1-28. | Article | PubMed

75. Gabathuler R: Approaches to transport therapeutic drugs across the blood-brain barrier to treat brain diseases. Neurobiol Dis 2010, 37:48-57. | Article | PubMed

76. Alonso A, Reinz E, Leuchs B, Kleinschmidt J, Fatar M, Geers B, Lentacker I, Hennerici MG, de Smedt SC and Meairs S: Focal Delivery of AAV2/1-transgenes Into the Rat Brain by Localized Ultrasoundinduced BBB Opening. Mol Ther Nucleic Acids 2013, 2:e73. | Article | PubMed Abstract | PubMed Full Text

77. Fortin D, Gendron C, Boudrias M and Garant MP: Enhanced chemotherapy delivery by intraarterial infusion and blood-brain barrier disruption in the treatment of cerebral metastasis. Cancer 2007, 109:751-60. | Article | PubMed

78. Kinoshita M, McDannold N, Jolesz FA and Hynynen K: Targeted delivery of antibodies through the blood-brain barrier by MRIguided focused ultrasound. Biochem Biophys Res Commun 2006, 340:1085-90. | Article | PubMed

79. Black KL and Ningaraj NS: Modulation of brain tumor capillaries for enhanced drug delivery selectively to brain tumor. Cancer Control 2004, 11:165-73. I Pdf | PubMed

80. Claes A, Idema AJ and Wesseling P: Diffuse glioma growth: a guerilla war. Acta Neuropathol 2007, 114:443-58. | Article | PubMed Abstract | PubMed Full Text

81. Garcia-Garcia E, Andrieux K, Gil S and Couvreur P: Colloidal carriers and blood-brain barrier (BBB) translocation: a way to deliver drugs to the brain? Int J Pharm 2005, 298:274-92. | Article | PubMed

82. Vandergrift WA, Patel SJ, Nicholas JS and Varma AK: Convectionenhanced delivery of immunotoxins and radioisotopes for treatment of malignant gliomas. Neurosurg Focus 2006, 20:E13. | Article | PubMed

83. Menei $P$, Benoit JP, Boisdron-Celle M, Fournier D, Mercier P and Guy $G$ : Drug targeting into the central nervous system by stereotactic implantation of biodegradable microspheres. Neurosurgery 1994, 34:1058-64; discussion 1064. | Article | PubMed

84. Grossman SA, Reinhard C, Colvin OM, Chasin M, Brundrett R, Tamargo RJ and Brem H: The intracerebral distribution of BCNU delivered by surgically implanted biodegradable polymers. $J$ Neurosurg 1992, 76:640-7. | Article | PubMed

85. Abbott NJ and Romero IA: Transporting therapeutics across the blood-brain barrier. Mol Med Today 1996, 2:106-13. | Article | PubMed

86. Johnson NJ, Hanson LR and Frey WH: Trigeminal pathways deliver a low molecular weight drug from the nose to the brain and orofacial structures. Mol Pharm 2010, 7:884-93 | Article | PubMed Abstract | PubMed Full Text

87. Pathan SA, Iqbal Z, Zaidi SM, Talegaonkar S, Vohra D, Jain GK, Azeem A, Jain N, Lalani JR, Khar RK and Ahmad FJ: CNS drug delivery systems: novel approaches. Recent Pat Drug Deliv Formul 2009, 3:71-89. | Article | PubMed

88. Hanson LR and Frey WH, 2nd: Intranasal delivery bypasses the blood-brain barrier to target therapeutic agents to the central nervous system and treat neurodegenerative disease. $B M C$ Neurosci 2008, 9 Suppl 3:S5. | Article | PubMed Abstract | PubMed Full Text

89. Pardridge WM: The blood-brain barrier: bottleneck in brain drug development. NeuroRx 2005, 2:3-14. | Article | PubMed Abstract | PubMed Full Text
90. Begley DJ: Delivery of therapeutic agents to the central nervous system: the problems and the possibilities. Pharmacol Ther 2004, 104:29-45. | Article | PubMed

91. Jones AR and Shusta EV: Blood-brain barrier transport of therapeutics via receptor-mediation. Pharm Res 2007, 24:1759-71. | Article | PubMed Abstract | PubMed Full Text

92. Beduneau A, Hindre F, Clavreul A, Leroux JC, Saulnier P and Benoit JP: Brain targeting using novel lipid nanovectors. J Control Release 2008, 126:44-9. | Article | PubMed

93. Costantino L, Gandolfi F, Tosi G, Rivasi F, Vandelli MA and Forni F: Peptide-derivatized biodegradable nanoparticles able to cross the blood-brain barrier. J Control Release 2005, 108:84-96. | Article | PubMed

94. Andrieux K, Garcia-Garcia E, Kim HR and Couvreur P: Colloidal Carriers: A Promising Way to Treat Central Nervous System Diseases. Journal of Nanoneuroscience 2009, 1: 17-34. | Article

95. Huwyler J, Cerletti A, Fricker G, Eberle AN and Drewe J: By-passing of P-glycoprotein using immunoliposomes. J Drug Target 2002, 10:73-9. | Article | PubMed

96. Chang J, Jallouli Y, Barras A, Dupont N and Betbeder D: Chapter 1 Drug delivery to the brain using colloidal carriers. Prog Brain Res 2009, 180:2-17. | Article | PubMed

97. Jones $\mathrm{M}$ and Leroux J: Polymeric micelles - a new generation of colloidal drug carriers. Eur J Pharm Biopharm 1999, 48:101-11. Article | PubMed

98. Ruiz MA, Clares B, Morales ME and Gallardo V: Vesicular lipidic systems, liposomes, PLO, and liposomes-PLO: characterization by electronic transmission microscopy. Drug Dev Ind Pharm 2008, 34:1269-76. | Article | PubMed

99. Roney C, Kulkarni P, Arora V, Antich P, Bonte F, Wu A, Mallikarjuana NN, Manohar S, Liang HF, Kulkarni AR, Sung HW, Sairam M and Aminabhavi TM: Targeted nanoparticles for drug delivery through the blood-brain barrier for Alzheimer's disease. J Control Release 2005, 108:193-214. | Article | PubMed

100. Olivier JC: Drug transport to brain with targeted nanoparticles. NeuroRx 2005, 2:108-19. | Article | PubMed Abstract | PubMed Full Text

101. Mishra B, Patel BB and Tiwari S: Colloidal nanocarriers: a review on formulation technology, types and applications toward targeted drug delivery. Nanomedicine 2010, 6:9-24. | Article | PubMed

102. Bae Y, Diezi TA, Zhao A and Kwon GS: Mixed polymeric micelles for combination cancer chemotherapy through the concurrent delivery of multiple chemotherapeutic agents. J Control Release 2007, 122:324-30. | Article | PubMed

103. Chapman M and Pascu SI: Nanomedicines design: approaches towards the imaging and therapy of brain tumours. Journal of Nanomedicine and Nanotechnology 2012, S4:0006. | Website

104. Provenzale JM and Mohs AM: Nanotechnology in NeurologyCurrent Status and Future Possibilities. US Neurology 2010, 6: 12-17. | Website

\section{Citation:}

Domínguez A, Álvarez A, Hilario E, Suarez-Merino $B$ and Goñi-de-Cerio F: Central nervous system diseases and the role of the blood-brain barrier in their treatment. Neurosci Discov 2013, 1:3. http://dx.doi.org/10.7243/2052-6946-1-3 